\title{
Combined effects of simvastatin and fibroblast growth factor-2 on the proliferation and differentiation of preosteoblasts
}

\author{
JUN-BEOM PARK

\begin{abstract}
Department of Periodontics, Seoul St. Mary's Hospital, College of Medicine,
\end{abstract} \\ The Catholic University of Korea, Seoul 137-701, Republic of Korea
}

Received June 26, 2013; Accepted July 12, 2013

DOI: $10.3892 /$ br.2013.137

\begin{abstract}
Simvastatin reportedly promotes osteoblastic and inhibits osteoclastic activity. It increases bone formation when injected subcutaneously over the calvaria in mice. It also increases cancellous bone volume in rats following oral administration. Fibroblast growth factor-2 (FGF-2), a member of the FGF family, is expressed by cells of the osteoblastic lineage. FGF-2 promotes osteoblast proliferation and it is secreted during the healing process of fractures or at bone surgery sites. FGF-2 reportedly regulates bone formation and osteoblast differentiation. In this study, the combined effects of simvastatin and FGF-2 on the proliferation and differentiation of preosteoblasts were investigated and an alkaline phosphatase (ALP) activity test was performed to assess the differentiation. Moreover, the expression of proteins associated with bone formation were measured using western blot analysis. The results demonstrated that the protein content of the cultures grown in osteogenic differentiation media in the presence of FGF-2 at a concentration of $20 \mathrm{ng} / \mathrm{ml}$ was higher compared to that of the untreated control cultures. ALP activity was decreased when cells were treated with FGF-2 (2 and $20 \mathrm{ng} / \mathrm{ml}$ ) and increased when cells were treated with simvastatin. The cultures grown in the presence of $1 \mu \mathrm{M}$ of simvastatin and $2 \mathrm{ng} / \mathrm{ml}$ of FGF-2 exhibited increased ALP activity when compared to that in the $2 \mathrm{ng} / \mathrm{ml}$ FGF-2-only group. The combination of $1.0 \mu \mathrm{M}$ simvastatin and $2 \mathrm{ng} / \mathrm{ml}$ FGF-2 achieved a higher estrogen receptor- $\alpha$ expression compared to the $2 \mathrm{ng} / \mathrm{ml}$ FGF-2-only group. Within the limits of this study, simvastatin enhanced osteoblast differentiation. However, the combined treatment with simvastatin and FGF-2 did not exert synergistic effects on osteoblast differentiation under the current experimental conditions. Future studies are required to evaluate divergent conditions and determine the
\end{abstract}

Correspondence to: Dr Jun-Beom Park, Department of Periodontics, Seoul St. Mary's Hospital, College of Medicine, The Catholic University of Korea, 222, Banpo-daero, Seocho-gu, Seoul 137-701, Republic of Korea

E-mail: jbassoonis@yahoo.co.kr

Key words: differentiation, fibroblast growth factor 2, osteoblast, proliferation, simvastatin selective timing and optimal dosage for the delivery of the agents.

\section{Introduction}

Simvastatin reportedly promotes osteoblastic activity and inhibits osteoclastic activity (1). It was shown to increase bone formation when injected subcutaneously over the calvaria in mice and has been demonstrated to increase cancellous bone volume in rats following oral administration (2). The successful use of simvastatin to promote bone formation in vivo reportedly depends upon the local concentration. There have been continuous efforts to determine an appropriate treatment protocol (1).

Fibroblast growth factor-2 (FGF-2), a member of the FGF family, is expressed by cells of the osteoblastic lineage. FGF-2 promotes osteoblast proliferation and is secreted during the healing process of fractures or at bone surgery sites (3). It was previously demonstrated that FGF-2 stimulates bone formation and osteoblast differentiation (4). However, the results of a previous study demonstrated that cultures grown in the presence of FGF-2 show an increased value for 3-[4,5-dimethylthiazol-2-yl]-2,5-diphenyltetrazolium bromide assay and a decreased value for alkaline phosphatase (ALP) activity (5). Similarly, FGF-2 was shown to inhibit bone morphogenetic protein-9 (BMP-9)-induced osteogenic differentiation by blocking BMP-9-induced Smads signaling (6).

In this study, the combined effects of simvastatin and FGF-2 on the proliferation and differentiation of preosteoblasts were investigated. The dose-dependent effect of simvastatin and FGF-2 on the proliferation of preosteoblasts was also evaluated. An ALP test was performed to assess differentiation and the expression of proteins associated with bone formation. Specifically, estrogen receptor- $\alpha$ (ER- $\alpha)$ and estrogen receptor- $\beta$ (ER- $\beta$ ) were measured using western blot analysis to evaluate the underlying mechanism. To the best of the author's knowledge, this study is the first to elucidate the combined effects of simvastatin and FGF-2 on the expression of ER- $\alpha$ in preosteoblasts.

\section{Materials and methods}

Cell culture. Mouse calvarial preosteoblasts (MC3T3-E1) were plated and maintained in an $\alpha$-Minimum Essential 
Medium ( $\alpha$ MEM; Invitrogen, Carlsbad, CA, USA) supplemented with $10 \%$ fetal bovine serum (Invitrogen), antibiotics (penicillin $100 \mathrm{U} / \mathrm{ml}$ and streptomycin $100 \mu \mathrm{g} / \mathrm{ml}$; Invitrogen), $10 \mathrm{mM} \beta$-glycerophosphate (Sigma, St. Louis, MO, USA) and $50 \mu \mathrm{g} / \mathrm{ml}$ ascorbic acid (Sigma). The cells were stimulated with simvastatin and FGF-2 at final concentrations of $0.1 \mu \mathrm{M}(\mathrm{S} 1)$ to $1 \mu \mathrm{M}$ (S2) for simvastatin and $2 \mathrm{ng} / \mathrm{ml}$ (F1) to $20 \mathrm{ng} / \mathrm{ml}$ (F2) for FGF-2. The cultures were maintained in a humidified atmosphere with $5 \% \mathrm{CO}_{2}$ and $95 \%$ air at $37^{\circ} \mathrm{C}$.

Protein measurement. Mouse cells were incubated in $\alpha \mathrm{MEM}$ in the presence of ascorbic acid and $\beta$-glycerophosphate for 2 days. The protein content was determined based on the Bradford method, using the Coomassie protein assay reagent with a series of bovine serum albumins used as internal standards (7). The absorbance was measured at $595 \mathrm{~nm}$ using a microplate spectrophotometer (BioTek, Winooski, VT, USA). The results are presented as the percentage of control values.

ALP activity assay. An ALP assay for osteoblast differentiation was performed after 2 days. The mouse preosteoblasts were lysed with a buffer containing $10 \mathrm{mM}$ Tris- $\mathrm{HCl}(\mathrm{pH}$ 7.4) and $0.2 \%$ Triton X-100. The samples were then sonicated for $20 \mathrm{sec}$ at $4^{\circ} \mathrm{C}$ and incubated with $10 \mathrm{mM}$ p-nitrophenylphosphate as a substrate in $100 \mathrm{mM}$ glycine buffer $(\mathrm{pH}$ 10.5) containing $1 \mathrm{mM} \mathrm{MgCl}{ }_{2}$ in a water bath at $37^{\circ} \mathrm{C}$. The absorbance was measured at $405 \mathrm{~nm}$ using a microplate reader (BioTek). In addition, ALP activity was normalized with respect to the total protein content $(8,9)$.

Western blot analysis. The preosteoblasts were washed twice with ice-cold phosphate-buffered saline (PBS) and solubilized with a lysis buffer. The lysates were centrifuged at $16,000 \mathrm{x} \mathrm{g}$ for $20 \mathrm{~min}$ at $4^{\circ} \mathrm{C}$ to remove the nuclear pellet. The supernatants were boiled in a sodium dodecyl sulfate sample buffer containing $\beta$-mercaptoethanol. Equal amounts of cell extracts were separated by sodium dodecyl sulfate-polyacrylamide gel electrophoresis and transferred onto polyvinylidene fluoride microporous membranes (Immobilon-P; Millipore Corporation, Billerica, MA, USA). The membranes were then blocked for at least $1 \mathrm{~h}$ in $0.1 \%$ (v/v) PBS and Tween-20 containing 5\% (w/v) powdered milk. Each membrane was probed with the desired antibodies, which were diluted in the same buffer at the recommended concentrations. Each membrane was incubated with horseradish peroxidase-conjugated secondary antibody. Subsequently, the washed blot was developed with enhanced chemiluminescence detection kits $(5,10)$. The mouse anti-ER- $\alpha$ and anti-ER- $\beta$ antibodies and the secondary antibodies conjugated with horseradish peroxidase were purchased from Cell Signaling Technology, Inc. (Danvers, MA, USA), Abcam (Cambridge, MA, USA), and Santa Cruz Biotechnology, Inc. (Santa Cruz, CA, USA).

\section{Results}

Protein measurement. The protein content in each culture plate was evaluated (Fig. 1). The results demonstrated that the protein content of the cultures grown in the osteogenic differentiation media in the presence of FGF-2 at $20 \mathrm{ng} / \mathrm{ml}$ was higher compared to that of the control cultures. However,

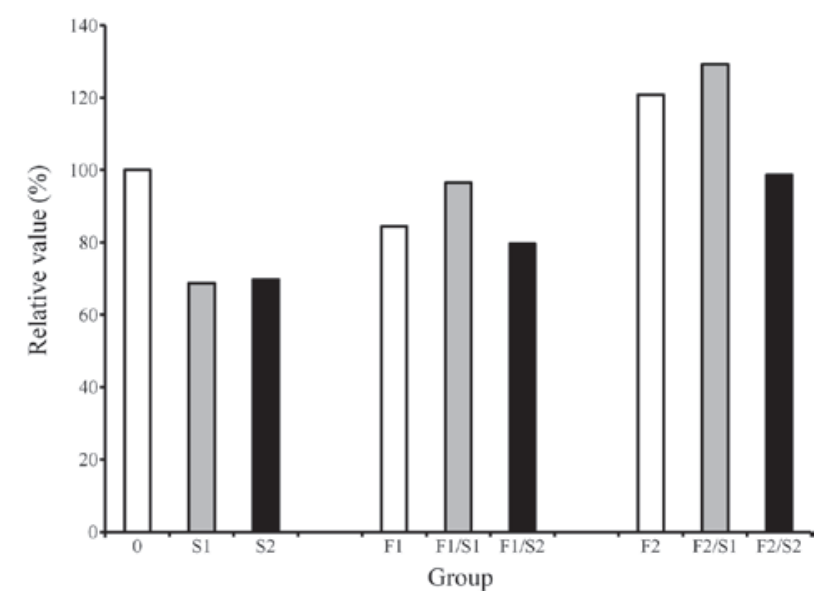

Figure 1. Determination of protein content. S1, $0.1 \mu \mathrm{M}$ simvastatin; $\mathrm{S} 2,1 \mu \mathrm{M}$ simvastatin; F1, 2 ng/ml FGF-2; F2, 20 ng/ml FGF-2. FGF, fibroblast growth factor.

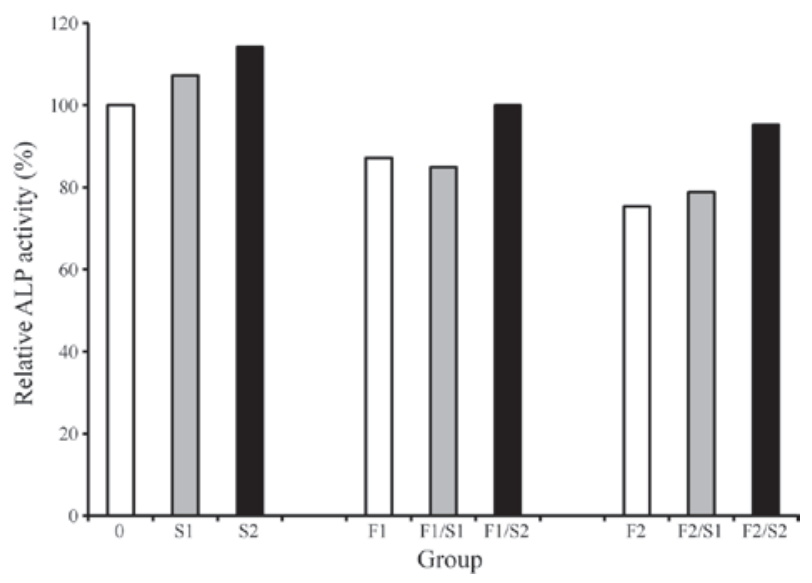

Figure 2. Relative value of alkaline phosphatase (ALP) activity. S1, $0.1 \mu \mathrm{M}$ simvastatin; S2, $1 \mu \mathrm{M}$ simvastatin; F1, 2 ng/ml FGF-2; F2, 20 ng/ml FGF-2. FGF, fibroblast growth factor.

the addition of $1.0 \mu \mathrm{M}$ simvastatin to the cultures uniformly led to a decrease in protein content compared to the simvastatin-unloaded group.

ALP activity assay. ALP activity decreased when cells were treated with FGF-2 (2 and $20 \mathrm{ng} / \mathrm{ml}$ ) (Fig. 2). The cultures grown in the presence of simvastatin $(0.1$ and $1.0 \mu \mathrm{M})$ exhibited an increase in ALP activity compared to the control cultures. Similarly, cultures grown in the presence of $1 \mu \mathrm{M}$ simvastatin and $2 \mathrm{ng} / \mathrm{ml}$ FGF-2 exhibited an increased value of ALP activity when compared to that of the $2 \mathrm{ng} / \mathrm{ml} \mathrm{FGF-2-only}$ group. The addition of $1 \mu \mathrm{M}$ simvastatin to $20 \mathrm{ng} / \mathrm{ml}$ of FGF-2 resulted in an increase in ALP activity compared to that of the $20 \mathrm{ng} / \mathrm{ml}$ FGF-2 group.

Western blot analysis. A western blot analysis was performed to detect the protein expression following treatment with simvastatin and FGF-2 (Fig. 3). The results demonstrated that the addition of simvastatin $(0.1$ and $1.0 \mu \mathrm{M})$ appeared to increase the expression of ER- $\alpha$. Similarly, the combination of $1.0 \mu \mathrm{M}$ simvastatin and $2 \mathrm{ng} / \mathrm{ml}$ FGF-2 led to a higher ER- $\alpha$ expression compared to that of the $2 \mathrm{ng} / \mathrm{ml}$ FGF-2-only group. 

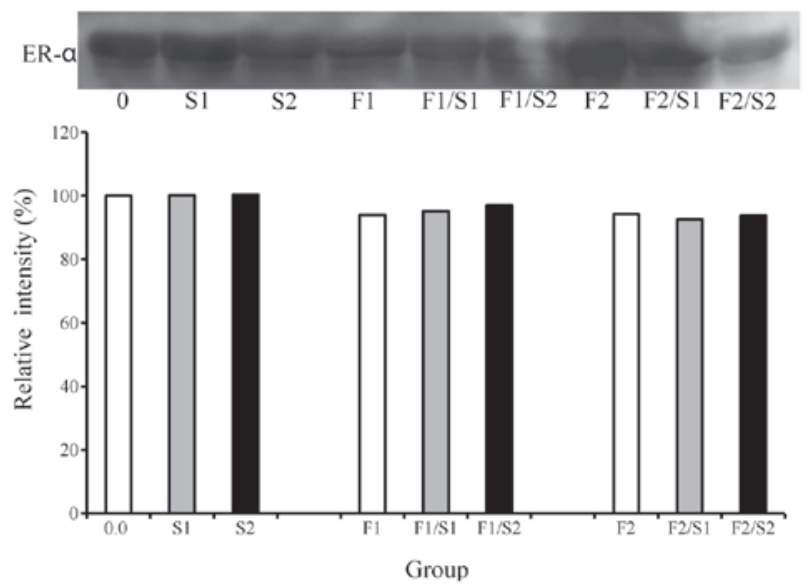

Figure 3. Western blot analysis of the protein expression of estrogen receptor- $\alpha$. A quantitative analysis of the protein expressions of estrogen receptor- $\alpha$ was conducted. S1, $0.1 \mu \mathrm{M}$ simvastatin; $\mathrm{S} 2,1 \mu \mathrm{M}$ simvastatin; F1, 2 ng/ml FGF-2; F2, 20 ng/ml FGF-2. FGF, fibroblast growth factor.

\section{Discussion}

In this study, the combined effects of simvastatin and FGF-2 on the protein content, differentiation and protein expression of preosteoblasts under predetermined concentrations ( 0.1 and $1.0 \mu \mathrm{M}$ simvastatin; 2 and $20 \mathrm{ng} / \mathrm{ml} \mathrm{FGF}-2$ ) were investigated. The mechanism of action of simvastatin and FGF-2 on the regulation of protein expression in mouse preosteoblasts was also investigated. In addition, evaluations were performed to determine whether the combination of simvastatin and FGF-2 produced effects additively, synergistically, or competitively.

An increase in protein content was achieved in the $20 \mathrm{ng} / \mathrm{ml}$ FGF-2 group under osteogenic differentiation media. This finding was consistent with the results of a previous study demonstrating that FGF-2 affected the proliferation of osteoblasts (5). The treatment of mouse preosteoblasts with simvastatin increased the level of ALP activity. Similarly, previous results demonstrated that cultures grown in the presence of simvastatin exhibited an increased value of ALP activity and mineralization (11). However, treatment with FGF-2 yielded a decreased value of ALP activity. This result was consistent with that of a previous study demonstrating that FGF-2 affected the differentiation of the cells under investigation (5). This study has demonstrated that the addition of $1.0 \mu \mathrm{M}$ simvastatin to $20 \mathrm{ng} / \mathrm{ml} \mathrm{FGF-2} \mathrm{led} \mathrm{to} \mathrm{an} \mathrm{increase} \mathrm{in}$ ALP activity compared to that of the $20 \mathrm{ng} / \mathrm{ml} \mathrm{FGF-2} \mathrm{group.}$ However, the value of ALP activity with the combination of $1.0 \mu \mathrm{M}$ simvastatin and $20 \mathrm{ng} / \mathrm{ml} \mathrm{FGF}-2$ did not reach the value of the untreated control group.

Western blot analysis was performed to detect the protein expression of ER- $\alpha$ and ER- $\beta$ to in order to provide information on potential additional mechanisms. The results demonstrated that the addition of simvastatin $(0.1$ and $1.0 \mu \mathrm{M})$ appeared to increase the expression of ER- $\alpha$. Similarly, the combination of $1.0 \mu \mathrm{M}$ simvastatin and $2 \mathrm{ng} / \mathrm{ml} \mathrm{FGF-2} \mathrm{led} \mathrm{to} \mathrm{a} \mathrm{higher} \mathrm{ER-} \alpha$ expression compared to that of the $2 \mathrm{ng} / \mathrm{ml} \mathrm{FGF-2-only} \mathrm{group.}$

Estrogens reportedly play a key role in bone formation and bind to estrogen receptors to exert their tissue-specific effects $(7,12)$. The findings of this study suggest that a combination of simvastatin and FGF-2 may partially exert effects on preosteoblasts through the expression of ER- $\alpha$ (11). The results regarding the effect of the combination of simvastatin and FGF-2 on osteoblastic proliferation and differentiation may be controversial due to the different culture conditions, type of cells, maturation stages of the cells under investigation and differences among species $(13,14)$.

Within the limits of this study, simvastatin enhanced osteoblast differentiation. However, the combined treatment with simvastatin and FGF-2 did not exert synergistic effects on osteoblast differentiation under the current experimental conditions. Therefore, future studies are required to evaluate divergent conditions and determine the selective timing and the optimal dosage for the delivery of these agents.

\section{Acknowledgements}

This study was supported by the Seoul St. Mary's Hospital Clinical Medicine Research Program year of 2013 through the Catholic University of Korea.

\section{References}

1. Park JB: The use of simvastatin in bone regeneration. Med Oral Patol Oral Cir Bucal 14: e485-e488, 2009.

2. Mundy G, Garrett R, Harris S, et al: Stimulation of bone formation in vitro and in rodents by statins. Science 286: 1946-1949, 1999.

3. Biver E, Soubrier AS, Thouverey C, et al: Fibroblast growth factor 2 inhibits up-regulation of bone morphogenic proteins and their receptors during osteoblastic differentiation of human mesenchymal stem cells. Biochem Biophys Res Commun 427: 737-742, 2012.

4. Zhou L and Ogata Y: Transcriptional regulation of the human bone sialoprotein gene by fibroblast growth factor 2. J Oral Sci 55: 63-70, 2013.

5. Park JB: Effects of fibroblast growth factor 2 on osteoblastic proliferation and differentiation by regulating bone morphogenetic protein receptor expression. J Craniofac Surg 22: 1880-1882, 2011

6. Song T, Wang W, Xu J, et al: Fibroblast growth factor 2 inhibits bone morphogenetic protein 9-induced osteogenic differentiation of mesenchymal stem cells by repressing Smads signaling and subsequently reducing Smads dependent up-regulation of ALK1 and ALK2. Int J Biochem Cell Biol 45: 1639-1646, 2013.

7. Park JB: Low dose of doxycyline promotes early differentiation of preosteoblasts by partially regulating the expression of estrogen receptors. J Surg Res 178: 737-742, 2012.

8. Park JB: The effects of dexamethasone, ascorbic acid, and $\beta$-glycerophosphate on osteoblastic differentiation by regulating estrogen receptor and osteopontin expression. J Surg Res 173: 99-104, 2012.

9. Park JB: Combination of simvastatin and bone morphogenetic protein-2 enhances differentiation of osteoblastic cells by regulating the expression of phospho-Smad1/5/8. Exp Ther Med 4: 303-306, 2012.

10. Park JB: Effects of doxycycline, minocycline, and tetracycline on cell proliferation, differentiation, and protein expression in osteoprecursor cells. J Craniofac Surg 22: 1839-1842, 2011.

11. Park JB, Zhang H, Lin CY, et al: Simvastatin maintains osteoblastic viability while promoting differentiation by partially regulating the expressions of estrogen receptors $\alpha$. J Surg Res 174: 278-283, 2012.

12. Pinzone JJ, Stevenson H, Strobl JS and Berg PE: Molecular and cellular determinants of estrogen receptor $\alpha$ expression. Mol Cell Biol 24: 4605-4612, 2004.

13. Kim CH, Cheng SL and Kim GS: Effects of dexamethasone on proliferation, activity, and cytokine secretion of normal human bone marrow stromal cells: possible mechanisms of glucocorticoid-induced bone loss. J Endocrinol 162: 371-379, 1999.

14. Ishida Y and Heersche JN: Glucocorticoid-induced osteoporosis: both in vivo and in vitro concentrations of glucocorticoids higher than physiological levels attenuate osteoblast differentiation. J Bone Miner Res 13: 1822-1826, 1998. 